\title{
Role of Cord Blood Albumin and Bilirubin In the prediction of Neonatal Jaundice
}

\author{
Prof.Dr. Ahmed Mahmoud Abd El Moktader,Prof.Dr.Nashwa Mamdouh \\ Samra, Prof.Dr.Howaida EL Menshawy, Lecturer Dr.Sara Ibrahim Abo \\ Elnor,Dr.Mostafa Mohamed Mohamed.
}

Pediatric Department, Clinical Pathology Department, Faculty of

Medicinc, Fayoum University, Egypt

Corresponding author : Dr.Mostafa Mohamed Mohamed

E-mail address : mostafaolwany14687@gmail.com

Tel : 01002652516

\begin{abstract}
Background:

Neonatal hyperbilirubinemia is commonest abnormal physical finding during the first week of life. It can be due to different etiologies. Most often it is physiological jaundice and the most common cause for readmission during the early neonatal period.
\end{abstract}

Objective: To predict the development of neonatal hyperbilirubinemia at birth using cord total bilirubin as a risk indicator.

Methods: cord bilirubin levels measurement at birth, Total serum bilirubin and direct serum bilirubin were measured after 72 hours of life with serum sampling of peripheral venous blood.
There is a correlation between cord serum bilirubin and neonatal hyperbilirubinemia in healthy term neonates. Cord serum bilirubin level of $<2.1 \mathrm{~g} / \mathrm{dl}$ has a sensitivity of $86.49 \%$ and specificity of $88.89 \%$, positive predictive value $82.05 \%$ and negative predictive value of $91.80 \%$ in predicting the risk of neonatal hyperbilirubinemia.

Conclusions: We can conclude that low cord bilirubin levels are probably safe for early discharge of the baby.

Keywords: Bilirubin, Cord blood.

\section{Introduction}


During the first week of life, neonatal jaundice is the commonest abnormal physical finding. More than two third of the newborn babies develop clinical jaundice(1).

Many efforts have been made to identify infants likely to develop neonatal jaundice.Reliable strategies can reduce hospital stay for normal babies and identify significant hyperbilirubinemia that may happen in the future.Hence, alternative strategies should be developed to predict the risk of significant jaundice as they can reduce hospital stay for normal babies and identify significant Neonatal hyperbilirubinemia that may happen in the future like umbilical cord bilirubin concentration at birth(2).

\section{Patient and method}

This Prospective cohort observational study was conducted on 100 neonates, delivered by normal or cesarean section in Fayoum University Hospital and Itsa Central Hospital.

\section{Inclusion criteria :}

- Neonates with gestational age 35 weeks or more.

- Any mode of delivery.

- both genders.

\section{Exclusion criteria :}

- Gestational age below 35 weeks.

- Any major congenital anomalies.

- Any major surgical conditions.

- $\mathrm{ABO}$ incompatability

\section{All cases were subjected to:}

\section{1- Full history taking with focusing on history for maternal illness, risk factors for hyperbilirubinemia e.g. $\mathrm{RH}$ or $\mathrm{ABO}$.}

\section{2- Examination of the newborn immediately after birth}

General and systemic examination.

\section{3-Laboratory investigation:}

\section{Type of specimen}

Cord blood samples $(3 \mathrm{ml})$ will be collected from all newborns that complied with the protocol inclusion criteria.The samples will be sent for the assaying of total, unconjugated, conjugated bilirubin, albumin levels and baby's blood group and rhesus.

Method of umbilical cord blood collection: After delivery of the newborn, the umbilical cord was double clamped and transected within 
10 seconds. As soon as the newborn was removed from the operative field, cord blood was collected as follows. The placenta-side part of the umbilical cord was held straight at a slight angle downward. After identification of a suitable puncture site, the umbilical cord was cleaned ,the umbilical vein was then punctured with sterile syring ,approximately $3 \mathrm{ml}$ of blood withdrawn from umbilical vein then put in a plain tube to be separated by centrifusion and then the serum tested for albumin \& bilirubin.

After 72 hours, 3-ml venous blood sample was withdrawn from the antecubital vein and collected in a plain centrifuge tube, allowed to clot in a $37^{\circ} \mathrm{C}$ water bath, and centrifuged for 10 minutes at 3000 g.Samples were protected from light. Haemolysed samples were avoided.

\section{$\underline{\text { Results }}$}

This Prospective cohort observational study was conducted on 100 neonates, delivered by normal or cesarean section in Fayoum University Hospital and Itsa Central Hospital.66\% of cases are females while $34 \%$ are males. $84 \%$ of cases delivered by CS with range of gestasional age was 36-40 weeks.

Table (1): Mean, SD and range of cord bilirubin and serum bilirubin in the studied neonates:

\begin{tabular}{|l|c|c|}
\hline \multicolumn{1}{|c|}{ Variable } & Mean \pm SD & Range \\
\hline At birth & $1.97 \pm 0.65$ & $0.7-3.8$ \\
\hline Total cord bilirubin & $0.25 \pm 0.15$ & $0.01-0.90$ \\
\hline Direct cord bilirubin & $13.91 \pm 5.75$ & $5.1-37.1$ \\
\hline After 72 hours & $1.05 \pm 0.49$ & $0.30-2.90$ \\
\hline Serum total bilirubin &
\end{tabular}

This table shows that Mean \pm SD and range of total cord bilirubin at birth are $(1.97 \pm 0.65) \&(0.7-3.8)$ respectively while Mean \pm SD and range of total cord bilirubin after 72 hours are (13.91 \pm 5.75$) \&(5.1-37.1)$ respectively while range of cord albumin after 72 hours is(2.0-4.2).

Table (2): Comparison between groups of patients (based on total cord bilirubin level) as regards serum bilirubin level: 


\begin{tabular}{|c|c|c|c|c|}
\hline \multirow[t]{2}{*}{$\begin{array}{l}\text { Biochemical } \\
\text { parameters }\end{array}$} & $\begin{array}{c}\text { Group A } \\
\text { Bilirubin } \\
>2.7 \mathrm{mg} / \mathrm{dl} \\
(\mathrm{N}=16) \\
\end{array}$ & $\begin{array}{c}\text { Group B } \\
\text { Bilirubin 2.0- } \\
2.7 \mathrm{mg} / \mathrm{dl} \\
(\mathrm{N}=25) \\
\end{array}$ & $\begin{array}{c}\text { Group C } \\
\text { Bilirubin }<0.2 \\
\text { mg/dl } \\
(\mathrm{N}=59) \\
\end{array}$ & \multirow[t]{2}{*}{ P-value } \\
\hline & \multicolumn{3}{|c|}{ Mean \pm SD } & \\
\hline $\begin{array}{l}\text { Serum Total } \\
\text { bilirubin mg/dl }\end{array}$ & $20.54 \pm 4.69$ & $17.00 \pm 3.87$ & $10.79 \pm 4.29$ & $<0.0001$ \\
\hline $\begin{array}{l}\text { Serum Direct } \\
\text { bilirubin } \mathrm{mg} / \mathrm{dl}\end{array}$ & $1.25 \pm 0.39$ & $1.26 \pm 0.54$ & $0.91 \pm 0.44$ & $0.002^{*}$ \\
\hline
\end{tabular}

\#One-way ANOVA

*Significant

This table illustrates that there is significant relation between total cord bilirubin level and serum total and direct bilirubin levels after 72 hours.

Table (3): The diagnostic accuracy of cord total bilirubin in predicting jaundice compared with neonatal hyperbilirubinemia:

\begin{tabular}{|c|c|c|c|c|}
\hline & $\begin{array}{c}\text { Sensitivity } \\
(\%) \\
95 \% \text { CI }\end{array}$ & $\begin{array}{c}\text { Specificity } \\
(\%) \\
95 \% \text { CI }\end{array}$ & $\begin{array}{c}\text { PPV } \\
(\%) \\
95 \% \mathrm{CI}\end{array}$ & $\begin{array}{c}\text { NPV } \\
(\%) \\
95 \% \mathrm{CI}\end{array}$ \\
\hline $\begin{array}{l}\text { Cord total bilirubin } \\
\text { level }>2.1\end{array}$ & $\begin{array}{c}86.49 \\
(71.2395 .46)\end{array}$ & $\begin{array}{c}88.89 \\
(78.44-95.41)\end{array}$ & $\begin{array}{c}82.05 \\
(69.21-90.29)\end{array}$ & $\begin{array}{c}91.80 \\
(83.15-96.22)\end{array}$ \\
\hline
\end{tabular}

Sensitivity: probability that a test result will be positive when the disease is present (true positive rate).

Specificity: probability that a test result will be negative when the disease is not present (true negative rate).

Positive predictive value: probability that the disease is present when the test is positive.

Negative predictive value: probability that the disease is not present when the test is negative.

This table illustrates that sensitivity, specificity, PPV and NPV of cord total bilirubin $>2.1 \mathrm{mg} / \mathrm{dl}$ are $86.49,88.89,82.05$ and 91.80 respectively. 


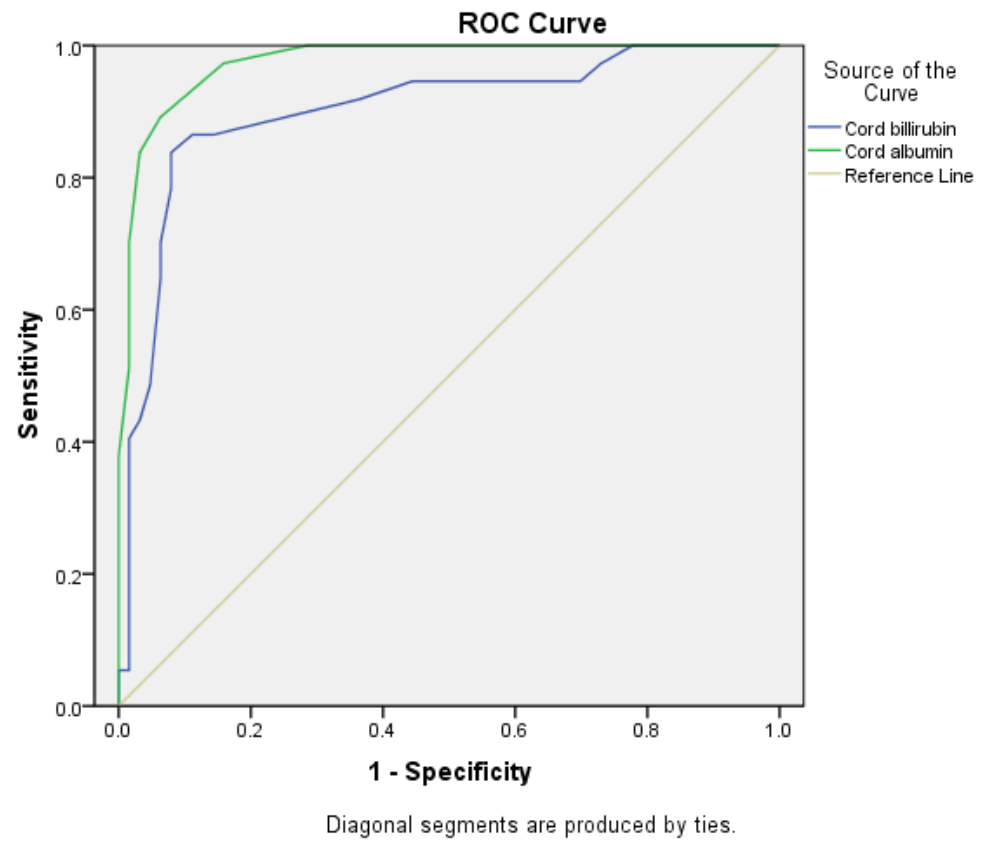

Figure(1): ROC curves for cord total bilirubin tests.

Taking a cut-off point of 2.1 for cord bilirubin showed sensitivity, specificity, PPV and NPV of $86.49,88.89,82.05$, and 91.80 respectively.

\section{$\underline{\text { Discussion }}$}

Jaundice or hyperbilirubinemia is a clinical condition that is caused due to the elevated serum concentration of bilirubin. In neonates, it is one of the major causes of concern. Its early detection is very difficult as neonatal jaundice may not appear until serum bilirubin exceeds 5 to $7 \mathrm{mg} / \mathrm{dl}(3)$.

Neonatal jaundice is one of the most common conditions requiring medical attention in newborn babies. About $60 \%$ of neonates born at term and $80 \%$ of neonate born before term (preterm) develop jaundice in the first week of life(4).

In the current study,100 healthy newborn were included of both genders; 66 females and 34 males.84\% delivered by CS .67\%born in FUH and $33 \%$ in ICH with gestasional age ranged from $36-40$ weeks $.37 \%$ of the studied neonates developed hyperbilirubinemia after $72 \mathrm{H}$ of delivery,34\% were required phototherapy and 3\% were required exchange transfusion.

Bilirubin is derived from the breakdown of hemecontaining 
proteins in the reticuloendothelial system. A normal newborn produces 6 to $10 \mathrm{mg}$ of bilirubin/ $\mathrm{kg} / \mathrm{day}$, greater than the adult production of 3 to 4 $\mathrm{mg} / \mathrm{kg} /$ day. Red blood cell hemoglobin is the major heme-containing protein. Hemoglobin released from senescent RBCs in the reticuloendothelial system accounts for $80 \%$ to $90 \%$ of bilirubin production(5).

Higher cord bilirubin levels among neonates who later became jaundiced compared to cord bilirubin levels in nonjaundiced neonates indicate that mechanisms of importance for the subsequent jaundice are already active in late fetal life. Nearly all fetal bilirubin is unconjugated, due to a limited ability of the fetal liver to conjugate bilirubin. In plasma, UCB is tightly bound to albumin, which is the dominant bilirubin binding protein in plasma. Under normal circumstances no bilirubin deposition in fetal tissue takes place. Unconjugated bilirubin is rapidly transferred to the maternal circulation by the placenta, whereas only small quantities of conjugated bilirubin cross the placenta. Thus bilirubin produced by the fetus is excreted by the mother, who presumably has a large reserve capacity for bilirubin excretion, and only minor differences in maternal bilirubin concentrations can be expected (6).

The appearance of clinical jaundice and the extent of jaundice were significantly correlated with cord blood bilirubin.In addition, higher cord blood bilirubin was significantly associated with the number of cases required referral for the management of neonatal hyperbilirubinemia.This finding was consistent with studies done by Nahar et al.,2009, Zeitoun et al.,2013, Ipek et al.,2012, Farhat et al.,2013, Trivedi et al.,2013,chary et al.,2014,Dwarampudi and Ramakrishna 2015 and Ahire et $a l ., 2016(3,7,8,9,1,10,11,12)$.

In the current study a total of 100 healthy terms and near term were categorized into three groups based on umbilical cord serum bilirubin levels: $16(16 \%)$ neonates in group A , 8 boys $\& 8$ girls; 25 (25\%) neonates in group B, 9 boys \& 16 girls; \& 59 (59\%) neonates in group C, 17 boys \& 42 girls.

In the current study,total cord bilirubin ranged from $0.7-3.8 \mathrm{mg} / \mathrm{dl}$ with mean $1.97 \pm 0.65$ while the serum total bilirubin after $72 \mathrm{~h}$ ranged from 5.1-37.1 with mean 13.91 \pm 5.75 there were significant relation between total 
cord bilirubin level and serum total bilirubin level after $72 \mathrm{~h}$ of delivery.

Phototherapy has a standard role in treating neonatal hyperbilirubinemia. It lowers the serum bilirubin level as it uses light energy from the light source in altering the structure and the shape of bilirubin, converting bilirubin into isomers that are water-soluble and are not dependent on the process of conjugation for their elimination from the body. Even when normal conjugation is deficient it converts bilirubin to molecules that can be easily excreted(13).

The study done by Hamdi $\boldsymbol{e t}$ al.,2012, showed no significant difference among the three groups regarding the mode of delivery, whether vaginal delivery or cesarean section that is agree with our study(14).

The current study showed that $4 \%$ of mothers had diabetes while only $2 \%$ had hypertension, $43 \% \%$ of them were At while only $2 \%$ were O- (table 6 ,figure 4).The studied neonates showed $41 \% \mathrm{~A}+$ while $18 \%$ were $\mathrm{AB}+$

Knüpfer et al.,2005 reported that for the prediction of further need of phototherapy using umbilical cord serum bilirubin cut-off level of 1.76 $\mathrm{mg} / \mathrm{dl}$, they found a sensitivity of $90 \%$ and NPV of $99.1 \%$, indicating that all patients with umbilical cord serum bilirubin values below $1.76 \mathrm{mg} / \mathrm{dl}$ $(443 / 1100$ or $40.2 \%)$ were at a very low risk of developing dangerous hyperbilirubinaemia(15).

Study by Farahat et $\boldsymbol{a l} ., 2013$, showed that umbilical cord serum bilirubin cut-off point $2 \mathrm{mg} / \mathrm{dl}$ had a sensitivity of $68.86 \%$ and specificity of $61.18 \%$ (9).while a study done by Nahar et al.,2009,showed that the cut-off point of $2.5 \mathrm{mg} / \mathrm{dl}$ had a sensitivity of $77 \%$,specificity of $98.6 \%$ and NPV of $96 \%(3)$.

The current study showed that the cut-off point of $2.1 \mathrm{mg} / \mathrm{dl}$ had a sensitivity of $86.49 \%$,specificity of $88.89 \%$ and NPV $91.80 \%$,so our study correlated with Nahar et al.,2009,Farhat et al.,2013, Knüpfer et al.,2005 and Venkatamurthy et al.,2014(3,9,15,16).

Hence we can conclude that low cord bilirubin levels are probably safe for early discharge of the baby

\section{Limitations of the study}

1. In the present study only full term healthy neonates were taken for the study. 
2. Babies are followed till only 72 hours of delivery.

\section{Conclusion}

- Use cord serum bilirubin as a risk factor of neonatal jaundice, which can give a clue to the possibility of severe jaundice during neonatal period.

- Cord serum bilirubin level of $>2.1 \mathrm{mg} / \mathrm{dl}$ risk factor of neonatal jaundice.

\section{$\underline{\text { Referances }}$}

(1) Trivedi DJ, Markande DM, Vidya BU, Bhat $M$ and Hegde PR(2013)Cord serum bilirubin and albumin in neonatal hyperbilirubinemia. Int $\mathrm{J}$ Int Sci Inn Tech Sec;2(2):39-42. 8.

\section{(2) Rostami}

$\mathbf{N}$, Mehrabi $\mathbf{Y}(\mathbf{2 0 0 5})$ Identifying the newborn at risk for developing significant hyperbilirubinemia by measuring cord bilirubin levels. J Arab Neonatal forum; 2:81-5.

(3) Nahar Z, Mannan SA, Dey SK, Mitra $U$ and Selimuzzaman SM(2009)The value of umbilical cord blood bilirubin measurement in predicting the development of significant hyperbilirubinemia in healthy Newborn. Bangladesh J Child Health 33(2): 50-54.

(4) Rennie J, Burman Roy S and Murphy MS(2010)Guideline Development Group. Neonatal jaundice: summary of NICE guidance. BMJ; 340: 1190-6.

(5) Stark AR and Bhutani VK(2016)Neonatal

Hyperbilirubinemia.Merck

Manuals Professional Edition ;1(1)336-346.

(6) Cohen RS, Wong RJ and Stevenson

DK(2010)Understanding Neonatal Jaundice: A Perspective on Causation, Pediatr Neonatol;51(3):143-148.

(7) Zeitoun AA , Elhagrasy HF and Abdelsatar(2013)D.M. Egyptian Pediatric Association Gazette;61, 23-30.

(8) Ipek IO, Bozaykut A, Çağrıl SC and Sezer RG(2012)Does cord blood bilirubin level help the physician in the decision of early postnatal discharge? J Mater Neonatal Med Eur Assoc Perinatal Med;25:106-11.

(9) Farhat A, Ghamsari A, Mohamadzadeh A, Khodadadi A and Rezaei M(2013)Does umbilical cord bilirubin level have 
predictive value in pathologic neonatal hyperbilirubinemia? Iran J Neonatol;4:11-8.

(10)Chary E, Bharadwaj N, Kumar PP, Vivekand N, Sailaja $\mathrm{V}$ and Harika B(2014)Umbilical cord blood bilirubin level measurement in predicting the development of significant hyperbilirubinemia. Indian J Mednodent Allied Sci 2014;6:13-21.

\section{(11)Dwarampudi $S$ and} Ramakrishna N(2015)Cord blood albumin and bilirubin levels as predictors in neonatal hyperbilirubinemia. Int $\mathrm{J}$ Pharma Biosci;3(4):211-20.

\section{(12) Ahire N, Sonawane R, Gaikwad}

\section{R, Patil S and Sonawane}

T(2016)Study of correlation of cord

blood bilirubin with neonatal hyperbilirubinemia. MVP J Med Sci;3:60-6.
(13) Chaudhry ER,Naveed AK,Rahim A and Chaudhry ZR(2016)Decreased cord blood albumin: A predictor of neonatal Jaundice,JIIMC 11(4):149-151.

(14) Hamdi N, Elgayar A and Salah MH(2012)Cord blood bilirubin as a predictor of neonatalhyperbilirubinemia. Med J Cairo Univ. 2012Jun;80(2):31-6.

(15) Knüpfer M, Pulzer F, Gebauer C, Robel-Tillig E and Vogtmann C(2005)Predictive value of umbilical cord blood bilirubin for postnatal hyperbilirubinaemia. Acta Paediatrica;94: 581-87.

(16) Venkatamurthy M, Murali SM and Mamatha S (2014)Evaluation of cord serum albumin level as a risk indicator in predicting neonatal Jaundice. Int J Health Info Med Res;1(2):9-11. 